\title{
Family Medicine Supervisors' Preferences for Improving Their Teaching Skills in Senior Care
}

Anik M.C. Giguere, PhD; Paule Lebel, MD, MSc; Michèle Morin, MD; Valérie Carnovale, PhD; Marie Meudec, PhD; Charo Rodriguez, MD, PhD; France Légaré, MD, PhD; Louise Champagne, MD; Bernard Martineau, MD, MA, PhD, DPES; Philippe Karazivan, MD, MA (Ed); Pierre J. Durand, MD

BACKGROUND AND OBJECTIVES: Many clinical supervisors in family medicine feel ill-equipped to teach senior care to their family medicine residents (trainees). We therefore sought to explore their preferred learning strategies for improving their clinical and teaching skills with regard to senior care.

METHODS: In this qualitative study, we conducted focus groups and interviews with supervisors from four family medicine clinics, to explore their preferred educational strategies. We selected four clinics using a maximum-variation strategy, based on a survey assessing continuing professional development (CPD) needs. The qualitative thematic analysis followed an inductive/deductive approach based on McGuire's attributes of persuasive communication.

RESULTS: The four focus groups and nine interviews with 53 supervisors (37 physicians, 9 nurses, 4 psychologists, 1 social worker, 1 nutritionist, 1 sexologist) revealed that supervisors preferred being trained by experienced trainers specialized in senior care, from various professional backgrounds, and knowledgeable about local community resources. They valued practical training the most, such as clinical case discussions based on real cases, clinical tools, and mentoring. The findings also suggest that training in senior care should be adapted to the supervisors' experience, profession, workload, and scope of intervention. Supervisors valued repeated CPD with longitudinal follow-up and easy access to trainers and to up-to-date training content.

CONCLUSIONS: The findings of this project will allow those who design CPD activities to adapt such activities to the preferences of supervisors, so as to improve their clinical and teaching skills in senior care. This, in turn, may help supervisors to embody an appealing professional role model for learners.

(Fam Med. 2021;53(4):267-74.)

doi: 10.22454/FamMed.2021.171325

n 2015, for the first time ever, the number of people in Canada aged 65 years or older exceeded the number of children. ${ }^{1}$ Moreover, according to the most recent projections, the share of people aged 65 and older will continue to increase and will account for $20 \%$ of the population by $2024 .^{1}$ This will have a professionals often find it difficult to care for seniors, due to medical complexities, patient vulnerability, administrative burdens, and interpersonal challenges. ${ }^{5}$ Furthermore, deficits exist with regard to basic knowledge in the care of seniors. ${ }^{6,7}$ This suggests there are shortcomings in the geriatric training currently available to family physicians, in terms of both undergraduate and continuing professional education. ${ }^{8}$ These challenges demonstrate the need for educational innovations to bolster the skills of primary care providers in senior care.

Residents often rely on their clinical supervisors as role models to acquire essential knowledge and skills. ${ }^{9,10}$ However, the lack of adequately trained teachers and

From the Department of Family and Emergency Medicine, Laval University, Quebec (Drs Giguere, Carnovale, and Légaré); Quebec Centre for Excellence on Aging (Drs Giguere, Morin, Meudec, and Durand); VITAM Research Center in Sustainable Health (Drs Giguere, and Légaré); Department of Family and Emergency Medicine, University of Montreal, Quebec (Drs Lebel and Karazivan); Department of Medicine, Laval University, Quebec (Dr Morin); Department of Anthropology, University of Toronto Scarborough, Ontario (Dr Meudec); Department of Family Medicine, McGill University, Quebec (Dr Rodriquez); Research Centre of the CHU de Quebec, Quebec (Dr Légaré); Department of Family and Emergency Medicine, University of Sherbrooke, Quebec (Drs Champagne and Martineau); and Department of Social and Preventive Medicine, Laval University, Quebec (Dr Durand). 
mentors has been identified as a barrier to the improvement of continuing professional development (CPD) in geriatric medicine. ${ }^{11,12}$ Thus, to improve the care of seniors, it is imperative that adequate CPD be provided to those who bear the responsibility for teaching.

Faculty development for geriatricoriented supervisors in family medicine can improve their skills in the care of older people and teaching of geriatrics, ${ }^{13}$ and increase their selfconfidence. ${ }^{14-16}$ However, there is a paucity of studies examining the preferred learning strategies of clinical supervisors in family medicine when it comes to improving their skills and their teaching abilities in senior care. We thus sought to understand how clinical supervisors in family medicine prefer to improve these skills.

\section{Methods \\ Study Design}

This was a qualitative study on the preferred learning strategies of clinical supervisors in family medicine (in Quebec, Canada) to hone their skills in senior care. It was approved by the research ethics committee of the research centre at the Centre Hospitalier Universitaire de Quebec (\#C13-06-1246), the Comité d'éthique de la recherche sur l'humain du Centre hospitalier universitaire de Sherbrooke (\#13-136-M1), the Institutional Review Board of McGill University (A08-E70-13B), and the Comité d'Éthique de la Recherche en Santé at Université de Montreal (\#13-079-CERES-D).

\section{Clinic Selection and Recruitment}

In a previous study in 43 family medicine teaching clinics, we used a cross-sectional survey to evaluate supervisors' perceived CPD requirements to teach their trainees how to manage clinical situations typical of senior care. ${ }^{17}$ Based on the results, we chose a purposive maximum-variation subsample of four clinics where supervisors reported extensive CPD needs for different clinical situations. Professionals of any profession who practice in family medicine clinics (nurses, social workers, pharmacists, psychologists) play formal or informal roles in the supervision of family medicine residents. Nurses may also supervise nurse trainees. Therefore, professionals of any professions practicing in family medicine clinics were included as study participants.

\section{Data Collection}

We conducted a 1-hour focus group with physicians in each of the four clinics. Additionally, we conducted interviews of roughly 30 minutes each, with supervisors other than physicians (eg, nurses, social workers), either individually or in dyads, as they possess a more diverse professional background, and are more difficult to gather in large homogeneous groups.

We used the same semistructured interview guide for all groups, to ask participants their preferred educational strategies, and their opinions about a CPD program designed to meet their training needs. The same experienced research professional (M.M.) conducted all focus groups/ interviews. Each discussion was recorded in audio format and transcribed verbatim. We compensated participants with lump sum payments of either $\$ 50$ or $\$ 100$, depending on the length of the interview.

\section{Analyses}

Three people performed a thematic qualitative data analysis using a hybrid deductive/inductive approach. ${ }^{18}$ The deductive analysis was inspired by McGuire's attributes of persuasive communication. ${ }^{19-21}$ McGuire proposes five communication attributes that can influence the persuasiveness of a message: its source (here, the trainer), the message to be communicated (here, the training content), the communication channels (here, the training channel), the characteristics of the audience (here, the supervisors), and the setting in which the communication is received (here, the learning context). We reported discussions relative to training content elsewhere. ${ }^{17}$ To explore possible themes and subthemes, the principal investigator (A.G.) and two research assistants (M.M., F.P.) independently went through a portion of the interviews, then reached a consensus. The transcripts were entered as project documents into a specialized software (NVivo 10, QSR International, Cambridge, MA), and the themes as nodes. One assistant (M.M.) applied these themes to all the interviews. We reached theoretical saturation as no new subthemes emerged during the last interviews. The principal investigator (A.G.) corroborated the final analysis.

\section{Results}

\section{Characteristics of Focus Group}

Participants

Of the 79 supervisors invited from the four clinics, 53 agreed to participate $(67 \%)$. We conducted four 1-hour focus groups-one per clinic-with 8 to 11 supervisors each. We also conducted one to three 30-minute interviews with providers other than physicians at each clinic, in smaller groups of one to three supervisors (total of nine interviews). The majority of participants were physicians $(70 \%)$ or nurses $(17 \%)$, and $13 \%$ had other professional backgrounds (Table 1). Most participants reported practicing an average of 31 hours per week $( \pm$ SD 13$)$ with an average of $41 \%( \pm$ SD $28 \%)$ of their practice time devoted to senior care.

\section{Preferred Learning Strategies}

The dominant perceptions of supervisors on the features of CPD activities conducive to improving their teaching skills in senior care are described in the following sections and summarized in Table 2. They are categorized according to the following attributes: trainers, training channels, learners, and learning context.

\section{Trainers}

Experience as field specialist dominated as the most valued feature of trainers in senior care. Most participants expressed that trainers should be specialists in senior care and knowledgeable about local community resources. One participant commented: 
Table 1: Characteristics of Study Participants

\begin{tabular}{|c|c|}
\hline Characteristic & $\begin{array}{l}\text { Participants } \\
\quad(\mathrm{N}=53)\end{array}$ \\
\hline \multicolumn{2}{|l|}{ Gender, n (\%) } \\
\hline Women & $40(75)$ \\
\hline \multicolumn{2}{|l|}{ Age (Years), n (\%) } \\
\hline$<30$ & $11(21)$ \\
\hline $30-39$ & $14(26)$ \\
\hline $40-49$ & $17(32)$ \\
\hline $50-59$ & $8(15)$ \\
\hline $60-69$ & $3(6)$ \\
\hline \multicolumn{2}{|l|}{ Profession, n (\%) } \\
\hline Physician & $37(70)$ \\
\hline Nurse & $9(17)$ \\
\hline Psychologist & $4(7)$ \\
\hline Social worker & $1(2)$ \\
\hline Nutritionist & $1(2)$ \\
\hline Sexologist & $1(2)$ \\
\hline \multicolumn{2}{|c|}{ Years of Practice, $n$ (\%) } \\
\hline$<10$ & $19(36)$ \\
\hline $10-19$ & $17(32)$ \\
\hline $20-29$ & $11(21)$ \\
\hline $30-39$ & $5(9)$ \\
\hline$\geq 40$ & $1(2)$ \\
\hline \multicolumn{2}{|c|}{ Hours of Practice/Week, Mean (SD) } \\
\hline Ambulatory care & $31.2(13.7)$ \\
\hline Home care & $0.6(1.5)$ \\
\hline Long-term care & $0.9(4.0)$ \\
\hline \multicolumn{2}{|c|}{ Hours of Supervision/Week, Mean (SD) } \\
\hline Ambulatory care & $9.7(10.5)$ \\
\hline Home care & $0.6(1.5)$ \\
\hline Long-term care & $0.7(4.2)$ \\
\hline
\end{tabular}

I find that important. People who are out in the field and see (patients) every day. More so than someone who's been teaching at a university for 50 years and hasn't set foot in a hospital and hasn't really treated elderly people. I find it pertinent. To have clinical cases, cases in their practice, and real situations on which to base ourselves. (Nonphysician health provider)

In all focus groups and interviews, the participants spontaneously discussed the trainers' professional supervisors mentioned that the trainer's profession was not an issue:

I believe that any professional who usually practices, for example, in a family medicine teaching clinic, and who specializes in or works with that particular clientele is qualified to provide such training. Because I believe practical experience is invaluable. (Nonphysician health provider)

Clinical supervisors generally believed that a group of interprofessional trainers should provide CPD on senior care, although one participant found such team teaching to be a barrier.

Opinions also differed about the trainer's origin. Some viewed the fact a trainer was from the local team as a facilitating aspect, whereas a trainer from outside the clinic was considered a facilitating factor for some but a barrier for others. Participants always reported CPD provided by peers as facilitating.

\section{Training Channels}

Generally, participants felt that CPD on senior care needed to be practical, presenting concrete cases and realistic scenarios, and by incorporating any theoretical concept into practice settings. This feature emerged systematically when participants discussed the training channels that they valued most, which were clinical case discussions, clinical tools, mentoring, and simulation workshops. For instance, they agreed about the value of clinical case discussions. They suggested using their own cases, cases based on real experiences, complex cases that raise particular concerns, or those adapted to senior care. One participant mentioned the importance of portraying situations representative of longterm care:

The people who are there are people who have complex health issues. It's not people who are a little bit sick that are in long-term care facilities. It's people who are very 
Table 2: Dominant Perceptions of Supervisors on the Features of CPD Activities for Improving Their Teaching Skills in Senior Care, as Categorized Into CPD Attributes (Trainer, Learning Channel, Learner, and Learning Context)

\begin{tabular}{|c|c|}
\hline CPD Attributes & Valuable Features of CPD Activities on Senior Care \\
\hline \multicolumn{2}{|r|}{ Trainer } \\
\hline Expertise & $\begin{array}{l}\text { - Experienced field specialist who still practices } \\
\text { - Expertise in geriatrics, whatever the profession } \\
\text { - Specialist of the discussed issues, expert of a specific intervention field }\end{array}$ \\
\hline Profession & $\begin{array}{l}\text { - Multidisciplinary, interdisciplinary, interprofessional supervision team } \\
\text { - Physician (family physician, neurologist, geriatrician who can adapt content to family } \\
\text { practice) } \\
\text { - Psychologist, pharmacist }\end{array}$ \\
\hline Channel & $\begin{array}{l}\text { - Clinical case discussion (complex cases based on real experiences) } \\
\text { - Clinical tools* } \\
\text { - Reenactments, simulation workshops } \\
\text { - Practical training (concrete, realistic) } \\
\text { - Mentoring, consultation, longitudinal follow-up } \\
\text { - Imall-group training } \\
\text { - Immersion/geriatric internship }\end{array}$ \\
\hline \multicolumn{2}{|r|}{ Learner } \\
\hline Workload/availability & $\begin{array}{l}\text { - Considers learners' availability and workload } \\
\text { - Planned well in advance with learners } \\
\text { - Allow learner to prepare the training in advance (in case of clinical case discussions) }\end{array}$ \\
\hline Experience & - Adapted to the learners' experience and competencies \\
\hline Profession & - Adapted to learners' profession (eg, physician, nurse) \\
\hline Field of intervention, mandate & $\begin{array}{l}\text { - Adapted to the learners' mandate (whether it is a field practiced by the learner or } \\
\text { not) } \\
\text { - Adapted to learners who teach or not }\end{array}$ \\
\hline Clientele & - Targets supervisors with an elderly clientele \\
\hline \multicolumn{2}{|r|}{ Learning Context } \\
\hline Duration & - Half-day \\
\hline Frequency & $\begin{array}{l}\text { - Once per month } \\
\text { - Once every } 2 \text { months } \\
\text { - Twice per year }\end{array}$ \\
\hline Timing & - Not in summer \\
\hline Longitudinal follow-up & $\begin{array}{l}\text { - Importance of regular iteration; repeated training necessary } \\
\text { - Longitudinal follow-up with continuous access to the trainers, long-term training }\end{array}$ \\
\hline Location & - On location \\
\hline Access to training content & $\begin{array}{l}\text { - Training content should be accessible, quickly and easily, from patients' home } \\
\text { - Content updates should be available (online or other) }\end{array}$ \\
\hline Access to trainers & - Trainers should remain accessible when needed \\
\hline
\end{tabular}

* The clinical tools category comprises: care protocols, clinical practice guidelines, diagnostic scales, databases, procedures, manuals, algorithms, checklists, lists of answers to most frequently asked questions, geriatric manual.

Abbreviation: CPD, continuing professional development.

sick, often with a very long list of pathologies. (Nonphysician health provider)

Several participants discussed how they valued clinical tools as facilitators to their learning and teaching experiences. We grouped together as "clinical tools" every document or computer program whose purpose is to guide the assessment, diagnosis, or treatment of a client-specific clinical problem, such as care protocols, clinical practice guidelines, diagnostic scales, databases, procedures, manuals, algorithms, checklists, and lists of answers to "most frequently asked questions."
Several participants perceived mentoring as an essential training channel to improve their skills in senior care. The participants felt that mentoring allowed for quick access to a resource person outside of training periods, for instance by phone, or on an as-needed basis. Supervisors also suggested that this relationship 
be developed over a longer-term period, even after the end of training. One participant stated:

In an ideal world (and I know it's not possible), there should be a resource person who's there when needed. Not just someone who comes in to give us a 3 -hour class... but a person we can turn to when we have questions (...). If we could at least have telephone access to a person we could consult with... (Nonphysician health provider)

Simulation workshops were also mentioned as being particularly useful to cover psychosocial issues, doctor-patient communication, and conflict management.

On the other hand, the participants discussed several other training channels, but disagreed amongst themselves as to their value. For example, they valued the accessibility, low cost, and flexibility of online training, but disliked the fact that such CPD requires regular updates. They held mixed views about conferences, presentations, and lectures. Participants valued these channels to integrate basic theoretical concepts, but felt they were not sufficiently hands-on, usually resulting in low retention of information. Supervisors also believed that coaching allows developing an individualized relationship with the trainer, which is favorable to problem solving and decision making, but they were reluctant to be supervised themselves. They were again divided regarding observation and feedback. They appreciated the opportunity to discuss their practice with an expert and compare themselves to a role model, but some expressed reservations about being observed:

I don't need to be observed with my patient. What I really need is to be able to discuss the case, to present my patient to some colleagues. This is what I'm dealing with. Should I go further than that? Are there other people I should involve that I haven't thought of? When discussing these aspects, the next steps become obvious. Of course! Why didn't I do that? (Physician)

Other training channels were discussed to a lesser extent, such as small-group training, internships in specialized geriatric units, interprofessional meetings, evidence-based discussions, simulated medical interviews, and supervision evaluation by peer supervisors.

\section{Learners}

Supervisors mentioned several of their own characteristics as learners that could influence their preferred learning strategies. Their experience, profession, training culture, field and mandate, workload, and availability all contributed to their preferred learning strategies. Some participants emphasized the value of adapting CPD to their field of practice and experience.

Additionally, the supervisors pointed out that nurses may require different CPD due to their specific fields of intervention, and because they have less clinical experience. One supervisor noted that nurses have fewer hours of mandatory training while another explained that their key role in settings where services intersect could explain their greater CPD needs. Supervisors suggested that CPD for nurses should target teaching skills and clinical skills specific to senior care. Moreover, nurse-specific CPD could benefit from the wealth of experience some nurses have in senior care.

\section{Learning Context}

There was consensus among participants with regard to the need to receive CPD over regularly spaced half days, preferably not in summer. Moreover, they considered it essential to adapt CPD to their schedules and to tailor it to each specific clinic's needs. Participants perceived that repeated and regular training with longitudinal follow-up and continuous access to trainers facilitated learning.
Participants also valued improved access to training content, such as up-to-date information, tools, and databases. They pointed to issues in accessing tools from home-care settings.

\section{Discussion}

We identified the preferred learning strategies of clinical supervisors in family medicine to improve their skills to deliver and teach senior care in Quebec. They preferred trainers from various professional backgrounds who were specialized in senior care, knowledgeable about local community resources, and possessed extensive experience. In terms of training channels, they valued clinical case discussions, clinical tools, and simulation workshops. Consideration of their characteristics as learners was a concern for most (ie, the need to adapt CPD to their experiences, profession, workload, and scope of intervention). In terms of learning context, they valued repeated CPD with longitudinal followup and easy access to trainers and to up-to-date training content.

Participants' preference for trainers with varying professional backgrounds, as well as the perceived value of interprofessional CPD, concur with previous findings on the benefits of interprofessional education (IPE) to improve senior care. ${ }^{22-25}$ Conversely, our findings also indicate that nurses might benefit from CPD sessions to meet their specific needs. A solution to this apparent disparity might be to combine interprofessional activities with sessions based on experience and scope of practice. Most participants also appreciated peer exchanges and getting training from a member of their own team. Peer-led CPD was previously demonstrated to be successful as a means to teach general practitioners how to manage specific geriatric symptoms. ${ }^{26}$ Interestingly, study participants did not mention patients and informal caregivers as potential trainers, despite ongoing experiments in this field. ${ }^{27}$ 
We found that learners' workload and availability should be carefully considered when offering CPD. Lack of time for participating in CPD is a recurrent theme in earlier studies on the barriers to CPD participation..$^{28,29}$ Officially incorporating CPD training into the supervisor's schedule by negotiating with their immediate superior has been proposed as a strategy to improve participation in CPD. ${ }^{30}$ Considering the importance of improving the abilities of family medicine teams to care for seniors, both from a patient perspective $\mathrm{e}^{31,32}$ and from a health system perspective, ${ }^{33,34}$ any CPD in senior care should preferably be endorsed by the supervisors' superior, as part of a public health program.

With regard to learning context, the participants discussed the importance of having easy access to training. They appreciated being able to reach an expert, at any time, for advice and continuous learning. For most supervisors, continuous and repeated CPD was a necessity, and they suggested having remote access to a network of experts over the long-term, for example through videoconferencing.

Our findings on the preferred learning channels concur with earlier studies that demonstrated the value of simulation and experiential learning to improve technical and nontechnical skills, attitude, and knowledge for senior care. ${ }^{35-37}$ A recent meta-analysis also showed that the more active CPD interventions are more effective at improving knowledge, performance, and outcomes. ${ }^{38}$ On the other hand, supervisors also valued clinical tools. Directories for the care of seniors, such as the McMaster Optimal Aging Portal could thus help meet professionals' needs.

In several interviews, mentoring emerged as a helpful strategy to improve supervisors' skills in senior care. Specifically, the participants expressed preferences for tailored, continuous, and longitudinal CPD with the same expert through iterations and repetitions, as well as unlimited access to the trainer for advice or feedback. All of these could be offered by a mentor, namely an experienced and trusted advisor who can provide guidance and support with the goal of improving the mentee's development. ${ }^{39}$ Mentoring could be especially important in the field of geriatrics, as $48 \%$ of physicians pursuing a career in geriatrics report they were influenced to do so by a specific role model or mentor. ${ }^{40}$ Senior care requires expertise that must balance a patient's clinical state and circumstances, relevant research evidence, and the patient's preferences. ${ }^{41}$ Expertise is acquired through motivation, repetition, gradual refinement, as well as experience with challenging situations and short-duration learning tasks with feedback and reflection. ${ }^{42}$ Mentors can play an integral role in some of these learning steps by helping supervisors face challenging situations, exposing them to short-duration learning tasks, and providing feedback on their management of complex geriatric cases. ${ }^{43,44}$

Overall, our findings highlight several features of CPD activities that meet the preferences of clinical supervisors when it comes to improving their teaching skills in senior care. Tailoring these activities carefully to supervisors' preferences could improve their motivation to participate in them, considering that motivational challenges are a recognized barrier to supervisors' participation in CPD on senior care. ${ }^{10}$ In addition, our findings suggest that training in senior care requires applied experiences that can only be encountered in real practice settings, guided by experienced field specialists. Well-tailored mentoring programs, real case discussions and clinical tools are therefore promising strategies that deserve to be explored further. These findings are consistent with those of a recent integrative review that shows that integrating practical applications improves the effectiveness of training. ${ }^{45}$

This study has limitations. First, we recruited participants from four university networks in the province of Quebec, therefore our study results are representative of this specific context only. However, as discussed, we found similarities with studies conducted in other settings. Second, although the overall number of supervisors interviewed was sufficient, for certain professions the number of participants was sometimes not enough (eg, nutritionist, sexologist) to draw conclusions about their specific preferences. Thirdly, we did not contact participants for their feedback on our interpretation of the data, however several of the coauthors are among the targeted participants and this could compensate somewhat for the lack of member checking. Finally, this work does not make it possible to assess the effectiveness of the learning strategies described, but only to learn about the preferences of supervisors with regard to these strategies. However, knowing these preferences could potentially allow adaptation of future CPD activities, and thus respect some principles of adult learning theory. ${ }^{46}$

\section{Conclusions}

This study provides some insights into the preferred learning strategies of clinical supervisors in family medicine to improve their skills and teaching abilities to care for seniors. We found that supervisors preferred that training be offered by trainers with extensive field experience, and knowledgeable about local community resources. It should also be adapted to learners' experience, profession, workload, and scope of intervention. It should be continuous and repeated, to allow feedback on the management of the learners' most complex cases. Lastly, training should be hands-on, and could comprise simulations, clinical case discussions representative of the more complex clinical situations, clinical tools specific to the care of seniors, and access to a mentor. While the current study provides considerable insight into the preferred learning strategies of primary health care 
providers, the combined efficacy of these remains untested. Future studies are required to determine whether implementing these strategies will improve supervisors' motivation to participate in such training, while offering the resources to improve their competencies and skills in teaching senior care, and ultimately allow them to embody an appealing professional role model for learners.

ACKNOWLEDGMENTS: The authors thank the staff of the participating clinic, Danielle Caron for her writing assistance, Françoise Proust and Pierre-Hugues Carmichaels for helping with quantitative data analyses, and Katherine Hastings for her writing assistance.

FINANCIAL SUPPORT: This project was funded by the Ministère de la Santé et des Services Sociaux du Québec, by the Research Chair in Aging at Laval University, by the three Departments of Family and Emergency Medicine of the Province of Quebec (Laval University, University of Montreal, University of Sherbrooke) and by McGill University's Department of Family Medicine. Author A.G. is funded by a Research Scholar Junior 2 Career Development Award by the Fonds de Recherche du Québec-Santé. Author F.L. holds a Canada Research Chair in Implementation of Shared Decision Making in Primary Care.

CORRESPONDING AUTHOR: Address correspondence to Anik Giguère, CIUSSS de la Capitale Nationale, VITAM - Centre de Recherche en Santé Durable, Pavillon Landry-Poulin, Entrée A-1-2, Bureau 2416, 2525, Chemin de la Canardière, Québec, QC G1J 0A4. 581-980-5677. Fax: 418-656-2465. anikgiguere@fmed.ulaval.ca.

\section{References}

1. Statistics Canada. Canada's population estimates: Age and sex, July 1, 2015. http:// www.statcan.gc.ca/daily-quotidien/150929/ dq150929b-eng.htm. Published 2015. Accessed January 7, 2021.

2. Canadian Institute for Health Information. Health Care in Canada 2011: A Focus on Seniors and Aging. Ottawa, Canada: Canadian Institute for Health Information; 2011. https:// secure.cihi.ca/free_products/HCIC_2011_seniors_report_en.pdf. Accessed January 7, 2021.

3. Lebel P, Champoux N, Dechêne G, et al. Repenser l'enseignement Des Soins Aux Personnes Âgées Pour Nos Futurs Médecins de Famille: Une Démarche Pas à Pas. Faculté de Médecine, Université de Montréal; 2013.

4. McGregor MJ, Sloan J. Realigning training with need: A case for mandatory family medicine resident experience in community-based care of the frail elderly. Can Fam Physician. 2014;60(8):697-699, 704-707.

5. Adams WL, Mcllvain HE, Lacy NL, et al. Primary care for elderly people: why do doctors find it so hard? Gerontologist. 2002;42(6):835842. doi:10.1093/geront/42.6.835
6. Wenger NS, Solomon DH, Roth CP, et al The quality of medical care provided to vulnerable community-dwelling older patients. Ann Intern Med. 2003;139(9):740-747. pii. doi:10.7326/0003-4819-139-9-200311040-00008

7. Lee L, Kasperski MJ, Weston WW. Building capacity for dementia care: training program to develop primary care memory clinics. Can Fam Physician. 2011;57(7):e249-e252.

8. Heckman GA, Hillier L, Manderson B, McKinnon-Wilson J, Santi SM, Stolee P. Developing an integrated system of care for frail seniors. Healthc Manage Forum. 2013;26(4):200-208 doi:10.1016/j.hcmf.2013.09.003

9. Jochemsen-van der Leeuw HGAR, van Dijk N, van Etten-Jamaludin FS, Wieringade Waard M. The attributes of the clinical trainer as a role model: a systematic review. Acad Med. 2013;88(1):26-34. doi:10.1097/ ACM.0b013e318276d070

10. Rubin CD, Stieglitz H, Vicioso B, Kirk L. Development of geriatrics-oriented faculty in general internal medicine. Ann Intern Med. 2003;139(7):615-620. doi:10.7326/0003-4819139-7-200310070-00035

11. Landefeld CS, Callahan CM, Woolard N. General internal medicine and geriatrics: building a foundation to improve the training of general internists in the care of older adults. Ann Intern Med. 2003;139(7):609-614 doi:10.7326/0003-4819-139-7-200310070-00034

12. Tanner CE, Eckstrom E, Desai SS, Joseph CL Ririe MR, Bowen JL. Uncovering frustrations. A qualitative needs assessment of academic general internists as geriatric care providers and teachers. J Gen Intern Med. 2006;21(1):5155. doi:10.1111/j.1525-1497.2005.0281.x

13. Willett RM, Boling PA, Meyers ME, Hoban JD, Lawson SR, Schlesinger JB. Professional development in geriatrics for community-based generalist faculty. J Am Geriatr Soc. 2007;55(2):300-304. doi:10.1111/j.15325415.2007.01050.x

14. Levine SA, Chao SH, Brett B, et al. Chief resident immersion training in the care of older adults: an innovative interspecialty education and leadership intervention. J Am Geriatr Soc. 2008;56(6):1140-1145. doi:10.1111/j.15325415.2008.01710.x

15. Pinheiro SO, White HK, Buhr GT, Elbert-Avila K, Cohen HJ, Heflin MT. Advancing Geriatrics Education Through a Faculty Development Program for Geriatrics-Oriented Clinician Educators. J Am Geriatr Soc. 2015;63(12):25802587. doi:10.1111/jgs.13824

16. Coogle CL, Hackett L, Owens MG, Ansello EF, Mathews JH. Perceived self-efficacy gains following an interprofessional faculty development programme in geriatrics education. $J$ Interprof Care. 2016;30(4):483-492. doi:10.108 0/13561820.2016.1177003

17. Giguere AMC, Lebel P, Morin M, et al. What Do Clinical Supervisors Require to Teach Residents in Family Medicine How to Care for Seniors? Can J Aging. 2018;37(1):32-49. doi:10.1017/S0714980817000460

18. Fereday J, Muir-Cochrane E. Demonstrating rigor using thematic analysis: A hybrid approach of inductive and deductive coding and theme development. Int J Qual Methods. 2006;5(1):80-92. doi:10.1177/160940690600500107
19. McGuire WJ. The nature of attitudes and attitude change. Handb Soc Psychol. 1969;3(2):136314.

20. McGuire WJ, Rice RE, Atkin CK. Input and output variables currently promising for constructing persuasive communications. Public Commun Campaign. 2001;3:22-48. doi:10.4135/9781452233260.n2

21. Wilson PM, Petticrew M, Calnan MW, Nazareth I. Disseminating research findings: what should researchers do? A systematic scoping review of conceptual frameworks. Implement Sci. 2010;5(1):91. doi:10.1186/1748-5908-5-91

22. Gould PR, Lee Y, Berkowitz S, Bronstein L. Impact of a collaborative interprofessional learning experience upon medical and social work students in geriatric health care. J Interprof Care. 2015;29(4):372-373. doi:10.3109/135618 20.2014.962128

23. Lash DB, Barnett MJ, Parekh N, Shieh A, Louie MC, Tang TTL. Perceived benefits and challenges of interprofessional education based on a multidisciplinary faculty member survey. Am J Pharm Educ. 2014;78(10):180. doi:10.5688/ ajpe7810180

24. World Health Organization. Framework for action on interprofessional education and collaborative practice. http://apps.who.int/iris/bitstream/10665/70185/1/WHO_HRH_HPN_10.3 eng.pdf. Published 2010. Accessed January 7 , 2021.

25. Keijsers CJPW, Dreher R, Tanner S, FordeJohnston C, Thompson S. Interprofessional education in geriatric medicine. Eur Geriatr Med. 2016;7(4):306-314. doi:10.1016/j.eurger.2016.01.011

26. Levine SA, Brett B, Robinson BE, et al. Practicing physician education in geriatrics: lessons learned from a train-the-trainer model. J Am Geriatr Soc. 2007;55(8):1281-1286. doi:10.1111/ j.1532-5415.2007.01205.x

27. Downar J, Chou YC, Ouellet D, et al. Survival duration among patients with a noncancer diagnosis admitted to a palliative care unit: a retrospective study. J Palliat Med. 2012;15(6):661-666. doi:10.1089/jpm.2011.0401

28. Jeong D, Presseau J, ElChamaa R, et al. Barriers and Facilitators to Self-Directed Learning in Continuing Professional Development for Physicians in Canada: A Scoping Review. Acad Med. 2018;93(8):1245-1254. doi:10.1097/ ACM. 0000000000002237

29. Regmi K, Jones L. A systematic review of the factors - enablers and barriers - affecting elearning in health sciences education. BMC Med Educ. 2020;20(1):91. doi:10.1186/s12909020-02007-6

30. Lawani MA, Côté L, Coudert L, et al. Professional training on shared decision making with older adults living with neurocognitive disorders: a mixed-methods implementation study. BMC Med Inform Decis Mak. 2020;20(1):189. doi:10.1186/s12911-020-01197-9

31. Giguere AMC, Farmanova E, Holroyd-Leduc JM, et al. Key stakeholders' views on the quality of care and services available to frail seniors in Canada. BMC Geriatr. 2018;18(1):290. doi:10.1186/s12877-018-0969-y 
32. Giguere AMC, Holroyd-Leduc JM, Straus SE, et al. Prioritization of indicators of the quality of care provided to frail seniors by key stakeholders from five Canadian provinces.

33. Frank C, Wilson CR. Models of primary care for frail patients. Can Fam Physician. 2015;61(7):601-606.

34. Valaitis R, Cleghorn L, Ploeg J, et al. Disconnected relationships between primary care and community-based health and social services and system navigation for older adults: a qualitative descriptive study. BMC Fam Pract. 2020;21(1):69. doi:10.1186/s12875-020-01143-8

35. Braude P, Reedy G, Dasgupta D, Dimmock V, Jaye P, Birns J. Evaluation of a simulation training programme for geriatric medicine. Age Ageing. 2015;44(4):677-682. doi:10.1093/ageing/ afv049

36. Diachun LL, Hillier LM, Stolee P. Interest in geriatric medicine in Canada: how can we secure a next generation of geriatricians? J Am Geriatr Soc. 2006;54(3):512-519. doi:10.1111/ j.1532-5415.2005.00610.x
37. Diachun LL, Dumbrell AC, Byrne K, Esbaugh J. ... But does it stick? Evaluating the durability of improved knowledge following an undergraduate experiential geriatrics learning session. J Am Geriatr Soc. 2006;54(4):696-701. doi:10.1111/j.1532-5415.2006.00656.x

38. Mansouri M, Lockyer J. A meta-analysis of continuing medical education effectiveness. J Contin Educ Health Prof. 2007;27(1):6-15. doi:10.1002/chp.88

39. Garmel GM. Mentoring in Emergency Medicine. In: Practical Teaching in Emergency Medicine. John Wiley \& Sons, Ltd; 2012:3556, doi:10.1002/9781118469804.ch4

40. Medina-Walpole A, Barker WH, Katz PR, Karuza J, Williams TF, Hall WJ. The current state of geriatric medicine: a national survey of fellowship-trained geriatricians, 1990 to 1998. J Am Geriatr Soc. 2002;50(5):949-955. doi:10.1046/j.1532-5415.2002.50225.x

41. Haynes RB, Devereaux PJ, Guyatt GH. Clinical expertise in the era of evidence-based medicine and patient choice. ACP J Club. 2002;136(2):A11-A14. doi:10.1136/ebm.7.2.36
42. Ericsson KA. Deliberate practice and acquisition of expert performance: a general overview. Acad Emerg Med. 2008;15(11):988-994. doi:10.1111/j.1553-2712.2008.00227.x

43. Allen TD, Shockley KM, Poteat L. Protégé anxiety attachment and feedback in mentoring relationships. J Vocat Behav. 2010;77(1):73-80. doi:10.1016/j.jvb.2010.02.007

44. Day R, Allen TD. The relationship between career motivation and self-efficacy with protégé career success. J Vocat Behav. 2004;64(1):72-91. doi:10.1016/S0001-8791(03)00036-8

45. Lawn S, Zhi X, Morello A. An integrative review of e-learning in the delivery of selfmanagement support training for health professionals. BMC Med Educ. 2017;17(1):183. doi:10.1186/s12909-017-1022-0

46. Kaufman DM. Applying educational theory in practice. BMJ. 2003;326(7382):213-216. doi:10.1136/bmj.326.7382.213 